\title{
The role of polysaccharide intercellular adhesin (PIA) in Staphylococcus epidermidis adhesion to host tissues and subsequent antibiotic tolerance
}

\author{
A. R. Costa • M. Henriques $\cdot$ R. Oliveira $\cdot$ J. Azeredo
}

Received: 21 February 2008 / Accepted: 1 December 2008 /Published online: 8 January 2009

(C) Springer-Verlag 2008

\begin{abstract}
The aim of this study was to determine the role of polysaccharide intercellular adhesin (PIA) in Staphylococcus epidermidis adhesion to host tissues and subsequent antibiotic tolerance. The adherence of S. epidermidis 1457 and the mutant defective in PIA production (1457-M10) to urinary epithelium and endothelium was estimated by colony counting. Minimum bactericidal concentration and mean reduction of cellular activity (XTT) following antibiotic exposure was determined for planktonic and adhered bacteria. $S$. epidermidis 1457 adhered to a greater extent to both cells than the mutant strain. The adhered strains had a significantly higher antimicrobial tolerance than their planktonic counterparts. The mutant strain was, in general, the most susceptible to the antibiotics assayed. In conclusion, PIA may influence $S$. epidermidis adherence to host tissues and their antimicrobial susceptibility. Initial adhesion may be the main step for the acquisition of resistance in $S$. epidermidis.
\end{abstract}

\section{Introduction}

In the last few decades, coagulase-negative staphylococcus (CoNS), in particular Staphylococcus epidermidis, have been associated with an increasing number of nosocomial infections involving indwelling devices [1,2]. Additionally, these bacteria also demonstrate the ability to adhere to host tissues, leading to serious infections [3]. Despite the increased clinical relevance of CoNS, their virulence factors

A. R. Costa $\cdot$ M. Henriques $\cdot$ R. Oliveira $\cdot$ J. Azeredo $(\bowtie)$ IBB - Institute for Biotechnology and Bioengineering, Centre of Biological Engineering, Universidade do Minho, 4710-057 Braga, Portugal

e-mail: jazeredo@deb.uminho.pt are not completely known [1, 4], especially those involved with host tissue infections. It should also be highlighted that adherence to host tissue might be influenced by distinct factors of those mediating materials adhesion and biofilm formation [5].

The ability to adhere and subsequently form biofilm on indwelling devices is among the potential virulence factors associated with $S$. epidermidis [4, 6, 7]. Indeed, biofilm formation frequently compromises the efficacy of implanted medical devices [8-10] and is also known to occur in native tissues, such as cartilage and cardiac tissue for S. aureus [11]. Biofilm formation can be divided into two main phases: initial adherence to the implant or tissue surface and biofilm accumulation involving cell proliferation and intracellular adhesion [12-14]. The molecule polysaccharide intercellular adhesin (PIA, synthesised by the ica operon $[15,16])$ has a very important role in the establishment of the biofilm structure being involved in cell-to-cell adhesion [17-21]. Gram-positive bacteria infections have become increasingly problematic due to the increased acquisition of resistance to antimicrobial agents $[22,23]$, hindering their treatment $[24,25]$. This aspect contributes to the increased importance of CoNS as pathogens, and is particularly relevant when biofilm formation occurs, since it was observed that bacteria embedded in this structure can tolerate antibiotic levels significantly higher than planktonic cells, exhibiting a dramatically increased resistance (up to 1,000-fold) [2628]. Several mechanisms have been suggested to explain this phenomenon, all based on the biofilm structure. However, the study of antimicrobial resistance has been neglected for bacteria in the first phase of biofilm formation (initial adhesion). In the adhered state, bacteria demonstrate deep physiologic and morphologic alterations comparatively to their planktonic phenotype, which may modify, and 
increase, antibiotic tolerance [29]. One of the purposes of this work was, therefore, to determine the susceptibility of adhered S. epidermidis cells to host tissues to five different antibiotics with different action mechanisms (the cell wall synthesis inhibitors vancomycin, cefazolin and dicloxacillin, the protein synthesis inhibitor tetracycline and the RNA synthesis inhibitor rifampicin).

It was also a goal of this study to determine the role of PIA in S. epidermidis adhesion to epithelium and endothelium and subsequent antibiotic tolerance.

\section{Materials and methods}

Bacterial strains and growth conditions

In this work, two strains of $S$. epidermidis were used: $S$. epidermidis 1457, a biofilm-forming strain [30], and its mutant $S$. epidermidis 1457-M10 [31]. This mutant strain was produced by the insertion of transposon $\operatorname{Tn} 917$ in the ica $\mathrm{A}$ gene of $S$. epidermidis 1457, which led to the inactivation of the ica $\mathrm{ADBC}$ gene and, consequently, to the complete abolition of PIA production and biofilm formation $[32,33]$. Both strains were kindly provided by Professor Gerald Pier from Harvard University.

Tryptic Soy Broth (TSB) and Tryptic Soy Agar (TSA) plates were prepared according to the manufacturer's instructions (Sigma-Aldrich). Strains were grown for $18 \mathrm{~h}$ (for adhesion and minimum bactericidal concentration [MBC] assays) or for $24 \mathrm{~h}$ (for XTT colorimetry assay) at $37^{\circ} \mathrm{C}$ with agitation $(110 \mathrm{rpm})$, in $30 \mathrm{ml}$ of TSB inoculated with bacterial cultures prepared in the previous day on TSA plates. Cells were harvested by centrifugation (for $5 \mathrm{~min}$ at 9,000 rpm and $4^{\circ} \mathrm{C}$ ), washed twice with phosphate-buffered saline (PBS, prepared with $10 \mathrm{mM} \mathrm{KH_{2 }} \mathrm{PO}_{4}$ (SigmaAldrich), $10 \mathrm{mM} \mathrm{K}{ }_{2} \mathrm{HPO}_{4}$ (Sigma-Aldrich) and $150 \mathrm{mM}$ $\mathrm{NaCl}$ (Sigma-Aldrich, $\mathrm{pH} 7.0$ ), resuspended in PBS and cellular concentration adjusted depending on the assay.

Animal cells and growth conditions

For the adhesion assays, primary human umbilical vein endothelial cells (HUVEC, C-003-5C, Cascade Biologics) and the established urinary epithelial cell line TCC-SUP (DSMZ) were used. HUVEC cells were grown in Medium 200 (Cascade Biologics) supplemented with 10\% low serum growth supplement (Cascade Biologics). TCC-SUP cells were grown in D-MEM medium supplemented with $15 \%$ fetal bovine serum (FBS, Gibco-Invitrogen) and 1\% antibiotic (Penicillin-Streptomycin, Gibco-Invitrogen). For the adherence studies, endothelial and epithelial cells were grown to confluence in 96-well microplates $(100 \mu \mathrm{l})$, at $37^{\circ} \mathrm{C}$ and $5 \% \mathrm{CO}_{2}$, with the medium described above for the appropriate cell type, without antibiotic. Approximately $5 \times 10^{3}$ HUVEC cells/well or $4 \times 10^{4}$ TCC-SUP cells/well were obtained at confluence.

Adhesion assay

Monolayers of HUVEC and TCC-SUP cells were washed with PBS and then inoculated with $100 \mu$ of the bacterial suspensions, yielding $1 \times 10^{8}$ bacteria/well. A control was performed with $100 \mu \mathrm{l}$ of PBS. After $2 \mathrm{~h}$ of contact at $37^{\circ} \mathrm{C}$ and $5 \% \mathrm{CO}_{2}$, monolayers were washed three times with PBS to remove non-adhered bacteria. Endothelial and epithelial cells were detached by the addition of trypsin/ EDTA (Cascade Biologics for HUVEC cells and GibcoInvitrogen for TCC-SUP cells). The number of adherent bacteria was determined by colony forming units (cfu) enumeration, plating 10-fold serial dilutions of well suspensions onto TSA plates, which were inoculated overnight at $37^{\circ} \mathrm{C}$. This experiment was repeated three times, in duplicate.

\section{Antibiotics}

In this study, five antibiotics were used, namely, cefazolin, vancomycin, dicloxacillin, tetracycline and rifampicin (Sigma-Aldrich). For the antimicrobial testing, solutions of $20,10,5,2.5,1.25$ and $0.75 \mathrm{mg} / \mathrm{L}$ (planktonic cells) and $1,000,500,250,100,50$ and $5 \mathrm{mg} / \mathrm{L}$ (adhered cells) were prepared, from stock solutions with concentrations of $2,000 \mathrm{mg} / \mathrm{L}$ (in sterile water), in Mueller Hinton Broth (Sigma-Aldrich), immediately before each experiment.

\section{MBC for planktonic cells}

For each strain, $5 \mu \mathrm{l}$ of bacterial suspension yielding $1 \times$ $10^{7} \mathrm{cfu} /$ well for 1457 and $4 \times 10^{6} \mathrm{cfu} /$ well for strain 1457 M10 (concentrations are identical to those obtained for adhered bacteria) were added to each well of a 96-well plate containing $100 \mu \mathrm{l}$ of different dilutions of each antibiotic and incubated at $37^{\circ} \mathrm{C}$ with agitation $(110 \mathrm{rpm})$ for $24 \mathrm{~h}$. Then, $10-\mu 1$ samples of each well were spread in TSA plates, which were incubated at $37^{\circ} \mathrm{C}$ for another $24 \mathrm{~h}$. MBC was determined as the minimal antibiotic concentration that did not allow colony formation. Experiments were repeated three times, in triplicate.

MBC for adhered cells

Antibiotic dilutions $(100 \mu \mathrm{l})$ were added to 96-well microplates containing bacteria adhered to HUVEC and TCCSUP cells and were incubated at $37^{\circ} \mathrm{C}$ and $5 \% \mathrm{CO}_{2}$ for $24 \mathrm{~h}$. Then, aliquots of $10 \mu \mathrm{l}$ from each well were spread in TSA plates and incubated at $37^{\circ} \mathrm{C}$ for $24 \mathrm{~h}$ for $\mathrm{MBC}$ 
determination. MBC was determined as described previously. Experiments were repeated three times, in triplicate.

\section{XTT colorimetry for planktonic cells}

Bacteria were exposed to each antibiotic (in the respective MBC) by the addition of $100 \mu \mathrm{l}$ of bacterial suspension (yielding $1 \times 10^{7} \mathrm{cfu}$ for strain 1457 and $4 \times 10^{6} \mathrm{cfu}$ for strain 1457-M10) to each well of a 96-well plate containing $100 \mu \mathrm{l}$ of antibiotics ( 2 times concentration). The plate was incubated at $37^{\circ} \mathrm{C}$ and $110 \mathrm{rpm}$ for $3 \mathrm{~h}$, after which $50 \mu \mathrm{l}$ of a solution containing $100 \mathrm{mg} / \mathrm{L}$ of XTT (Sigma-Aldrich) and $10 \mathrm{mg} / \mathrm{L}$ of PMS (Sigma-Aldrich) were added to each well. The plate was then incubated at $37^{\circ} \mathrm{C}$ for $3 \mathrm{~h}$ in the dark, with agitation $(110 \mathrm{rpm})$. Cells were allowed to settle for $15 \mathrm{~min}$ before spectrophotometric readings and $150 \mu \mathrm{l}$ of the supernatant from each well were transferred to a new well plate and the absorbance was measured at $490 \mathrm{~nm}$. XTT solutions resulting from cell suspensions not exposed to antibiotics were used as controls. All experiments were repeated two times, in triplicate. Results of the reduction of cellular activity were expressed as the difference in absorbance readings at $490 \mathrm{~nm}$ between controls without antibiotic and antibiotic-treated strains, per $\mu \mathrm{g}$ of antibiotic used, in order to standardise the antimicrobial agents concentration.

\section{XTT colorimetry for adhered bacterial cells}

Antibiotics $(200 \mu \mathrm{l})$ at the MBC were added to a 96-well microplate containing bacteria adhered to HUVEC or TCCSUP cells and incubated at $37^{\circ} \mathrm{C}$ and $110 \mathrm{rpm}$ for $3 \mathrm{~h}$. Then, $50 \mu \mathrm{l}$ of a solution containing $100 \mathrm{mg} / \mathrm{L}$ of XTT and $10 \mathrm{mg} / \mathrm{L}$ PMS were added to each well. Microplates were incubated for additional $3 \mathrm{~h}$ at $37^{\circ} \mathrm{C}$ in the dark. Cells were allowed to settle before spectrophotometric readings and $150 \mu \mathrm{l}$ of the supernatant from each well were transferred to a new well plate, with absorbance measured at $490 \mathrm{~nm}$. Bacteria adhered to HUVEC or TCC-SUP cells and not exposed to antibiotics were used as controls. All experiments were repeated two times, in triplicate. Results of the mean reduction of cellular activity were expressed as the difference in absorbance readings at $490 \mathrm{~nm}$ between controls without antibiotic and antibiotic-treated strains, per $\mu \mathrm{g}$ of antibiotic used.

\section{Statistical analysis}

Statistical analysis was performed using SPSS software (Statistical Package for the Social Sciences). Adhesion results were analysed using one-way analysis of variance (ANOVA) and XTT colorimetry assays were analysed using one-way ANOVA with Bonferroni test. All tests were performed with a confidence level of $95 \%$.

\section{Results}

Adhesion to endothelium and urinary epithelium

For the mutant strain, S. epidermidis 1457-M10, the number of bacteria adhered to both tissues (Fig. 1) was significantly lower $(P=0)$ than for strain 1457 . Both strains demonstrated significantly higher $(P=0)$ extent of adhesion to endothelial cells when compared with urinary epithelial cells. Figure 1 allows the comparison of the strains' adherence to endothelium and epithelium.

Antibiotic susceptibility assessed by MBC

Table 1 presents the MBC of five antibiotics for $S$. epidermidis strains on the planktonic or adhered states. Adhered bacteria, either to endothelium or epithelium, had
Fig. 1 Mean number of Staphylococcus epidermidis 1457 and 1457-M10 colony forming units (cfu) adhered to: a endothelial cells and $\mathbf{b}$ urinary epithelial cells

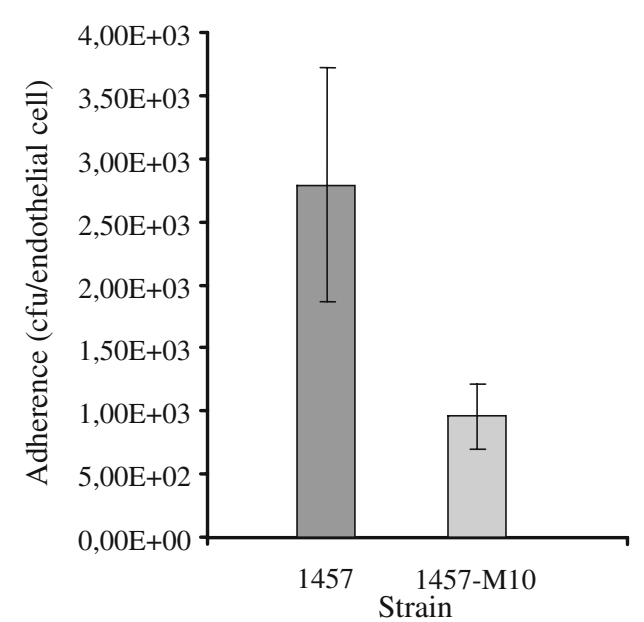

(a)

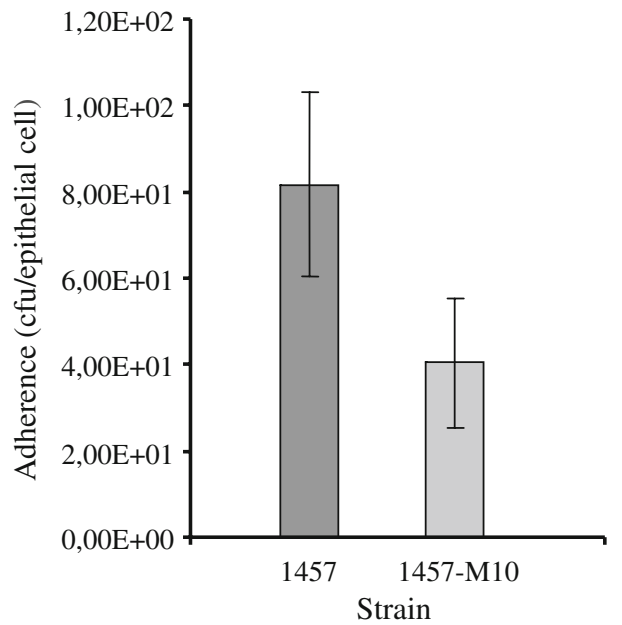

(b) 
Table 1 Minimum bactericidal concentration (MBC) of different antibiotics for Staphylococcus epidermidis 1457 and S. epidermidis 1457-M10 on the planktonic and adhered states

\begin{tabular}{|c|c|c|c|c|c|c|}
\hline \multirow[t]{3}{*}{ Antibiotic } & \multicolumn{6}{|c|}{$\mathrm{MBC}(\mathrm{mg} / \mathrm{L})$} \\
\hline & \multicolumn{2}{|l|}{ Planktonic } & \multicolumn{2}{|c|}{ Adhered to endothelial cells } & \multicolumn{2}{|c|}{ Adhered to urinary epithelial cells } \\
\hline & 1457 & 1457-M10 & 1457 & 1457-M10 & 1457 & $1457-M 10$ \\
\hline Cefazolin & $<0.75$ & $<0.75$ & $500-1,000$ & $500-1,000$ & $500-1,000$ & $500-1,000$ \\
\hline Vancomycin & $10-20$ & $10-20$ & $500-1,000$ & $500-1,000$ & $500-1,000$ & $500-1,000$ \\
\hline Dicloxacillin & $1.75-2.5$ & $1.75-2.5$ & $500-1,000$ & $500-1,000$ & $500-1,000$ & $500-1,000$ \\
\hline Tetracycline & $10-20$ & $10-20$ & $100-250$ & $100-250$ & $100-250$ & $100-250$ \\
\hline Rifampicin & $0.75-1.25$ & $0.75-1.25$ & $5-50$ & $5-50$ & $5-50$ & $5-50$ \\
\hline
\end{tabular}

higher MBC values than planktonic bacteria, indicating a lower susceptibility. The RNA inhibitor, rifampicin, was the most efficient antibiotic against adhered bacteria.

Antibiotic susceptibility assessed by XTT colorimetry

The mean reduction in metabolic activity for both $S$. epidermidis strains, after exposure of planktonic or adhered cells to the MBC of the antibiotics, was also assayed (Table 2). Cellular activity reduction for adhered bacteria was significantly lower than for planktonic bacteria, confirming the $\mathrm{MBC}$ results that indicate a higher tolerance for adhered cells.

Table 3 shows the significance values obtained by the statistical comparison of susceptibility between $S$. epidermidis strains for the different antibiotics and bacterial states. Significant differences were observed for vancomycin, dicloxacillin and tetracycline for bacteria in the planktonic and adhered states. For cefazolin, significant differences were detected for adhered bacteria, while for rifampicin, strains susceptibility was significantly different only when they were adhered to urinary epithelium.

\section{Discussion}

S. epidermidis has been established as one of the most important pathogens associated with nosocomial infections, particularly those involving indwelling devices [1, 4]. Furthermore, these microorganisms have also demonstrated the ability to adhere to human tissues, causing highmortality infections [3]. Bacterial adhesion is thought to be one of the critical steps for host tissue infections, but the current knowledge about this phenomenon, and the factors influencing it, is still very limited.

In this study, it was evaluated the adherence of two $S$. epidermidis strains that differ only on their ability to produce PIA, an important cell component on biofilms

Table 2 Mean reduction of cellular activity, assessed by XTT, after $3 \mathrm{~h}$ of exposure to the MBC of the antibiotics, of S. epidermidis 1457 and $S$. epidermidis 1457-M10 on planktonic and adhered states,

expressed as the difference in absorbance values with and without antibiotic treatment per $\mu \mathrm{g}$ of antibiotic

\begin{tabular}{|c|c|c|c|c|c|c|}
\hline \multirow[t]{3}{*}{ Antibiotic } & \multicolumn{6}{|c|}{$\mathrm{ABS}_{490 \mathrm{~nm}}( \pm \mathrm{SD})$} \\
\hline & \multicolumn{2}{|l|}{ Planktonic } & \multicolumn{2}{|c|}{ Adhered to endothelium } & \multicolumn{2}{|c|}{ Adhered to urinary epithelium } \\
\hline & 1457 & 1457-M10 & 1457 & 1457-M10 & 1457 & 1457-M10 \\
\hline CFZ & $\begin{array}{l}4.35 \times 10^{-1} \\
\pm 1.58 \times 10^{-2}\end{array}$ & $\begin{array}{l}4.16 \times 10^{-1} \\
\pm 2.22 \times 10^{-2}\end{array}$ & $\begin{array}{l}1.70 \times 10^{-4} \\
\pm 7.07 \times 10^{-7}\end{array}$ & $\begin{array}{l}1.84 \times 10^{-4} \\
\pm 5.00 \times 10^{-6}\end{array}$ & $\begin{array}{l}4.39 \times 10^{-5} \\
\pm 6.35 \times 10^{-6}\end{array}$ & $\begin{array}{l}5.92 \times 10^{-5} \\
\pm 5.17 \times 10^{-6}\end{array}$ \\
\hline VAN & $\begin{array}{l}1.50 \times 10^{-2} \\
\pm 1.24 \times 10^{-3}\end{array}$ & $\begin{array}{l}1.64 \times 10^{-2} \\
\pm 7.07 \times 10^{-4}\end{array}$ & $\begin{array}{l}1.51 \times 10^{-4} \\
\pm 1.44 \times 10^{-5}\end{array}$ & $\begin{array}{l}2.66 \times 10^{-4} \\
\pm 1.84 \times 10^{-5}\end{array}$ & $\begin{array}{l}1.09 \times 10^{-4} \\
\pm 1.50 \times 10^{-5}\end{array}$ & $\begin{array}{l}6.18 \times 10^{-5} \\
\pm 7.74 \times 10^{-6}\end{array}$ \\
\hline DCX & $\begin{array}{l}8.75 \times 10^{-2} \\
\pm 6.41 \times 10^{-3}\end{array}$ & $\begin{array}{l}1.13 \times 10^{-1} \\
\pm 4.48 \times 10^{-3}\end{array}$ & $\begin{array}{l}1.61 \times 10^{-4} \\
\pm 5.13 \times 10^{-6}\end{array}$ & $\begin{array}{l}1.98 \times 10^{-4} \\
\pm 2.65 \times 10^{-6}\end{array}$ & $\begin{array}{l}5.14 \times 10^{-5} \\
\pm 4.89 \times 10^{-6}\end{array}$ & $\begin{array}{l}3.27 \times 10^{-5} \\
\pm 5.82 \times 10^{-6}\end{array}$ \\
\hline TET & $\begin{array}{l}7.14 \times 10^{-3} \\
\pm 7.69 \times 10^{-4}\end{array}$ & $\begin{array}{l}8.29 \times 10^{-3} \\
\pm 8.49 \times 10^{-4}\end{array}$ & $\begin{array}{l}6.24 \times 10^{-4} \\
\pm 2.20 \times 10^{-5}\end{array}$ & $\begin{array}{l}8.73 \times 10^{-4} \\
\pm 4.06 \times 10^{-5}\end{array}$ & $\begin{array}{l}1.44 \times 10^{-4} \\
\pm 3.08 \times 10^{-5}\end{array}$ & $\begin{array}{l}4.78 \times 10^{-4} \\
\pm 2.60 \times 10^{-5}\end{array}$ \\
\hline RIF & $\begin{array}{l}2.18 \times 10^{-1} \\
\pm 1.32 \times 10^{-2}\end{array}$ & $\begin{array}{l}2.14 \times 10^{-1} \\
\pm 1.30 \times 10^{-2}\end{array}$ & $\begin{array}{l}2.38 \times 10^{-3} \\
\pm 1.36 \times 10^{-4}\end{array}$ & $\begin{array}{l}2.36 \times 10^{-3} \\
\pm 1.22 \times 10^{-4}\end{array}$ & $\begin{array}{l}4.10 \times 10^{-3} \\
\pm 2.80 \times 10^{-4}\end{array}$ & $\begin{array}{l}5.59 \times 10^{-3} \\
\pm 2.98 \times 10^{-4}\end{array}$ \\
\hline
\end{tabular}

CFZ: cefazolin; VAN: vancomycin; DCX: dicloxacillin; TET: tetracycline; RIF: rifampicin 
Table 3 Significance $(P)$ values obtained for the comparison of metabolic activity reduction between S. epidermidis 1457 and $S$. epidermidis 1457-M10 for the different antibiotics and bacterial states

\begin{tabular}{llll}
\hline Antibiotic & Planktonic & Adhered to endothelium & Adhered to urinary epithelium \\
\hline Cefazolin & 0.121 & $\mathbf{0 . 0 3 0}$ & $\mathbf{0 . 0 0 1}$ \\
Vancomycin & $\mathbf{0 . 0 4 1}$ & $\mathbf{0 . 0 0 1}$ & $\mathbf{0 . 0 0 0}$ \\
Dicloxacillin & $\mathbf{0 . 0 0 0}$ & $\mathbf{0 . 0 0 0}$ & $\mathbf{0 . 0 0 0}$ \\
Tetracycline & $\mathbf{0 . 0 3 4}$ & $\mathbf{0 . 0 0 1}$ & $\mathbf{0 . 0 0 0}$ \\
Rifampicin & 0.580 & 0.859 & $\mathbf{0 . 0 0 0}$ \\
\hline
\end{tabular}

Significant $P$-values $(P<0.05)$ are represented in bold

formation, whose influence in the initial adhesion is not entirely understood. S. epidermidis 1457, the PIA producer, demonstrated a higher adherence to host cells than the mutant strain (unable to produce PIA), with significant differences of about 3-fold to endothelium and 2-fold to urinary epithelium (Fig. 1). Previously, Rupp et al. [34] reported a lower adherence of this mutant strain to subcutaneous catheters implanted in mice, which, in conjugation with the results presented, suggest that the 1457-M10 strain adheres in a lower extension than the 1457 strain to both biomaterials and host cells, either in vivo or in vitro.

Adherence to substrates is known to be influenced by several aspects, including bacterial and host cells, and even environmental factors. Among them are the specific interactions established between microorganism ligands and complementary receptors in host cells. Extracellular polymers, such as, for example, PIA, may act as ligand and, consequently, influence the rate and extension of microbial adhesion [35]. Hence, the lower adherence of the mutant strain to endothelial and urinary epithelial cells may be explained by its inability to produce PIA, preventing possible interactions between this exopolymer and host cell surface components.

PIA's role on initial adhesion has been an object of discussion for years: several authors [18-21] support the view that this polymer is only responsible for biofilm cell accumulation; others $[10,36]$ have a divergent opinion, suggesting that PIA influence on adhesion is not well established, showing that the assays' conditions (such as dynamic or static conditions; long- or short-term adherence) are responsible for the extent of adhesion. Furthermore, most studies are related to biomaterials adhesion, with a very small knowledge about adherence to host tissues. The results obtained in the present study corroborate the PIA relation with the early stages of adherence to host tissues.

Comparing the adhesion to both tissues (Fig. 1), the $S$. epidermidis strains demonstrated a significantly higher adherence to endothelial cells. This may be a consequence of the host cell's own characteristics, such as surface hydrophobicity or surface proteins expression (fibronectin, fibrinogen, vitronectin), that may influence interactions with microbial surfaces. However, the percentage of bacterial cells that adhered to host cells in relation to the initial inoculum was very small for both $S$. epidermidis strains, as demonstrated by the percentage of initial inoculum adhered $(3.5 \%$ and $14.7 \%$ for the 1457 strain, and $1.9 \%$ and $5.4 \%$ for the $1457-\mathrm{M} 10$ strain). This is in accordance with previous studies, which indicate a lower $S$. epidermidis propensity to adhere to urinary tissue [37, 38] and to endothelial cells [39].

In the last few years, antimicrobial resistance has been established as a serious problem for the treatment of infections, especially those involving biofilms. For this reason, the most recent antimicrobial resistance studies concern bacteria embedded in a biofilm structure. However, some authors $[9,27,40]$ contradict this approach, highlighting the importance of the evaluation of bacterial resistance in the first phase of biofilm formation, which consists of initial adhesion. Furthermore, antimicrobial susceptibility is usually assessed by determining the minimal inhibitory concentration (MIC). However, Williams et al. demonstrated that adhered bacteria may be able to evade the bactericidal effect of antibiotics [29], and, therefore, although more resistant, they exhibit no MIC alterations, which may lead to the misinterpretation of susceptibility. Additionally, there had been an increased number of immunocompromised patients with CoNS infections, and treatment with antibiotics at their MIC seemed to be ineffective, since, at this concentration, the efficiency of the antibiotic relies on the collaboration of the immune system to completely eliminate the infection. Therefore, these aspects emphasise the need to evaluate the bactericidal effect of the antibiotics, and not their MIC, which may be assessed by MBC determinations [41].

MBC results for $S$. epidermidis strains (Table 1) demonstrate that bacteria which adhered to both host tissues have a much lower susceptibility to antibiotics than planktonic bacteria. This is particularly true for cell wall synthesis inhibitors (cefazolin, vancomycin and dicloxacillin), for which differences of about two times more were detected. Furthermore, it was also detected a higher 
resistance of adhered bacteria to both tetracycline (protein inhibitor) and rifampicin (RNA inhibitor), although the susceptibility to antibiotics appeared to be less affected by the sessile phenotype. The results obtained are in agreement with a previous study of Cerca et al. concerning $S$. epidermidis biofilms and involving the same antibiotics [27]. It was also observed that rifampicin displayed the best efficacy against bacteria adhered to host cells, and that it was the only one with a possible clinical application for the treatment of CoNS infections, since its peek serum concentration $(10 \mathrm{mg} / \mathrm{L}$ [27]) is the only one within the MBC range determined.

The XTT results (Table 2) allowed the same conclusions as MBC, indicating a significantly higher resistance for adhered bacteria, with rifampicin showing the lowest reduction of activity.

Therefore, both MBC and XTT results provide evidence that the adhered phenotype offers protection against several antibiotics, suggesting that biofilm structure is not the main factor leading to increased tolerance. Indeed, the initial adhesion may be the most important step for the acquisition of this low susceptible state. Such observations contradict the mechanisms previously proposed to explain the increased resistance, which are mainly based on biofilm structure. These include a lower or incomplete penetration of the antibiotic due to a diffusion barrier, phenotypic variability within the biofilm and slow cell growth within the biofilm $[9,27,28]$. Slow growth within the biofilm could be a possible explanation for the higher resistance displayed by adhered bacteria, which was observed by Williams et al. for $S$. aureus in the adhered state (without biofilm formation) [29]. However, since this could only be valid for antibiotics whose action depends on the cell growth rate, such as cell wall inhibitors, the fact that rifampicin activity is also dependent on the growth rate and no significant differences regarding this antibiotic susceptibility were detected between adhered and planktonic bacteria implies that it is not a valid explanation for the increased tolerance. Hence, other mechanisms must be involved in the acquisition of antibiotic tolerance by adhered bacteria, which may rely on the physiological state of individual bacteria and not on the physical effect of the biofilm matrix [29]. Furthermore, the susceptibility of the adhered phenotype appears to be affected by the antibiotic mechanism of action, since cell wall inhibitors present a reduced activity against adhered bacteria, and protein and RNA inhibitors remain relatively efficient.

The XTT results allow a correct comparison between strains susceptibility, since it allows the analysis of the antibiotic effect on bacteria viability for a specific antibiotic concentration. Although with some exceptions, significant differences (Table 3 ) were observed between strains, with the mutant $1457-$ M10 presenting a higher susceptibility
(Tables 2 and 3). Since the only distinction between the strains consists of their ability to produce PIA, this exopolymer might be the explanation for this difference. It could confer some sort of protection against antibiotics, and, consequently, the inability of the mutant strain to produce PIA might cause it to be more susceptible.

Acknowledgements No special acknowledgements are due.

\section{References}

1. von Eiff C, Peters G, Heilmann C (2002) Pathogenesis of infections due to coagulase-negative staphylococci. Lancet Infect Dis 2:677-685 doi:10.1016/S1473-3099(02)00438-3

2. Holgers KM, Ljungh A (1999) Cell surface characteristics of microbiological isolates from human percutaneous titanium implants in the head and neck. Biomaterials 20:1319-1326 doi:10.1016/S0142-9612(99)00033-2

3. Van Belkum A, Kools-Sijmons M, Verbrugh H (2002) Attachment of Staphylococcus aureus to eukaryotic cells and experimental pitfalls in staphylococcal adherence assays: a critical appraisal. J Microbiol Methods 48:19-42 doi:10.1016/S0167-7012(01)00342-6

4. von Eiff C, Heilmann C, Peters G (1999) New aspects in the molecular basis of polymer-associated infections due to staphylococci. Eur J Clin Microbiol Infect Dis 18:843-846 doi:10.1007/ s100960050417

5. Rupp ME, Ulphani JS, Fey PD et al (1999) Characterization of Staphylococcus epidermidis polysaccharide intercellular adhesin/ hemagglutinin in the pathogenesis of intravascular catheterassociated infection in a rat model. Infect Immun 67:2656-2659

6. McKenney D, Hübner J, Muller E et al (1998) The ica locus of Staphylococcus epidermidis encodes production of the capsular polysaccharide/adhesin. Infect Immun 66:4711-4720

7. Mack D (1999) Molecular mechanisms of Staphylococcus epidermidis biofilm formation. J Hosp Infect 43:113-125 doi:10.1016/S0195-6701(99)90074-9

8. Ahanotu EN, Stone JH, Mcallister SK et al (2001) Vancomycin resistance among strains of Staphylococcus epidermidis: effects on adherence to silicone. Curr Microbiol 43:124-128 doi:10.1007/ s002840010273

9. Mah TFC, O'Toole GA (2001) Mechanisms of biofilm resistance to antimicrobial agents. Trends Microbiol 9:34-39 doi:10.1016/ S0966-842X(00)01913-2

10. Cerca N, Pier GB, Vilanova M et al (2005) Quantitative analysis of adhesion and biofilm formation on hydrophilic and hydrophobic surfaces of clinical isolates of Staphylococcus epidermidis. Res Microbiol 156:506-514 doi:10.1016/j.resmic.2005.01.007

11. Götz F (2002) Staphylococcus and biofilms. Mol Microbiol 43:1367-1378 doi:10.1046/j.1365-2958.2002.02827.x

12. Götz F, Peters G (2000) Colonization of medical devices by coagulase-negative staphylococci. In: Waldvogel FA, Bisno AL (eds) Infections associated with indwelling medical devices, 3rd edn. ASM Press, Washington, DC

13. Mack D, Rohde H, Dobinsky S et al (2000) Identification of three essential regulatory gene loci governing expression of Staphylococcus epidermidis polysaccharide intercellular adhesin and biofilm formation. Infect Immun 68:3799-3807 doi:10.1128/ IAI.68.7.3799-3807.2000

14. Foster TJ (2002) Surface protein adhesins of staphylococci. In: Wilson M (ed) Bacterial adhesion to host tissues: mechanisms and consequences. Advances in Molecular and Cellular Microbiology. Cambridge University Press 
15. Heilmann C, Schweitzer O, Gerke C et al (1996) Molecular basis of intercellular adhesion in the biofilm-forming Staphylococcus epidermidis. Mol Microbiol 20:1083-1091 doi:10.1111/j.13652958.1996.tb02548.x

16. Gerke C, Kraft A, Süssmuth R et al (1998) Characterization of the $\mathrm{N}$-acetylglucosaminyltransferase activity involved in the biosynthesis of the Staphylococcus epidermidis polysaccharide intercellular adhesin. J Biol Chem 273:18586-18593 doi:10.1074/ jbc.273.29.18586

17. Rupp ME, Fey PD, Heilmann C et al (2001) Characterization of the importance of Staphylococcus epidermidis autolysin and polysaccharide intercellular adhesin in the pathogenesis of intravascular catheter-associated infection in a rat model. J Infect Dis 183:1038-1042 doi:10.1086/319279

18. Mack D, Nedelmann M, Krokotsch A et al (1994) Characterization of transposon mutants of biofilm-producing Staphylococcus epidermidis impaired in the accumulative phase of biofilm production: genetic identification of a hexosamine-containing polysaccharide intercellular adhesin. Infect Immun 62:3244-3253

19. Mack D, Fischer W, Krokotsch A et al (1996) The intercellular adhesin involved in biofilm accumulation of Staphylococcus epidermidis is a linear $\beta$-1,6-linked glucosaminoglycan: purification and structural analysis. J Bacteriol 178:175-183

20. Maira-Litrán T, Kropec A, Abeygunawardana C et al (2002) Immunochemical properties of the staphylococcal poly- $N$-acetylglucosamine surface polysaccharide. Infect Immun 70:4433-4440 doi:10.1128/IAI.70.8.4433-4440.2002

21. Sadovskaya I, Vinogradov E, Flahaut S et al (2005) Extracellular carbohydrate-containing polymers of a model biofilm-producing strain, Staphylococcus epidermidis RP62A. Infect Immun 73:3007-3017 doi:10.1128/IAI.73.5.3007-3017.2005

22. Mack D, Sabottke A, Dobinsky S et al (2002) Differential expression of methicillin resistance by different biofilm-negative Staphylococcus epidermidis transposon mutant classes. Antimicrob Agents Chemother 46:178-183 doi:10.1128/AAC.46.1.178183.2002

23. de Feiter PW, Jacobs JA, Jacobs MJ et al (2005) Successful treatment of Staphylococcus epidermidis prosthetic valve endocarditis with linezolid after failure of treatment with oxacillin, gentamicin, rifampicin, vancomycin, and fusidic acid regimens. Scand J Infect Dis 37:173-176 doi:10.1080/00365540410021018

24. O'Gara JP, Humphreys H (2001) Staphylococcus epidermidis biofilms: importance and implications. J Med Microbiol 50:582587

25. Michelim L, Lahude M, Araújo PR et al (2005) Pathogenic factors and antimicrobial resistance of Staphylococcus epidermidis associated with nosocomial infections occurring in intensive care units. Braz J Microbiol 36:17-23 doi:10.1590/S1517-8382200 5000100004

26. Stewart PS, Costerton JW (2001) Antibiotic resistance of bacteria in biofilms. Lancet 358:135-138 doi:10.1016/S0140-6736(01) 05321-1

27. Cerca N, Martins S, Cerca F et al (2005) Comparative assessment of antibiotic susceptibility of coagulase-negative staphylococci in biofilm versus planktonic culture as assessed by bacterial enumeration or rapid XTT colorimetry. J Antimicrob Chemother 56:331-336 doi:10.1093/jac/dki217

28. Cerca N, Martins S, Pier GB et al (2005) The relationship between inhibition of bacterial adhesion to a solid surface by sub-MICs of antibiotics and subsequent development of a biofilm. Res Microbiol 156:650-655 doi:10.1016/j.resmic.2005.02.004

29. Williams I, Venables WA, Lloyd D et al (1997) The effects of adherence to silicone surfaces on antibiotic susceptibility in Staphylococcus aureus. Microbiology 143:2407-2413

30. Mack D, Siemssen N, Laufs R (1992) Parallel induction by glucose of adherence and a polysaccharide antigen specific for plastic-adherent Staphylococcus epidermidis: evidence for functional relation to intercellular adhesion. Infect Immun 60:20482057

31. Mack D, Nedelmann M, Krokotsch A et al (1994) Characterization of transposon mutants of biofilm-producing Staphylococcus epidermidis impaired in the accumulative phase of biofilm production: genetic identification of a hexosamine-containing polysaccharide intercellular adhesin. Infect Immun 62:3244-3253

32. Knobloch JK, Nedelmann M, Kiel K et al (2003) Establishment of an arbitrary PCR for rapid identification of Tn917 insertion sites in Staphylococcus epidermidis: characterization of biofilm-negative and nonmucoid mutants. Appl Environ Microbiol 69:5812-5818 doi:10.1128/AEM.69.10.5812-5818.2003

33. Mack D, Riedewald J, Rohde H et al (1999) Essential functional role of the polysaccharide intercellular adhesin of Staphylococcus epidermidis in hemagglutination. Infect Immun 67:1004-1008

34. Rupp ME, Ulphani JS, Fey PD et al (1999) Characterization of the importance of polysaccharide intercellular adhesin/hemagglutinin of Staphylococcus epidermidis in the pathogenesis of biomaterialbased infection in a mouse foreign body infection model. Infect Immun 67:2627-2632

35. Donlan RM (2002) Biofilms: microbial life on surfaces. Emerg Infect Dis 8:881-890

36. Mohamed N, Teeters MA, Patti JM et al (1999) Inhibition of Staphylococcus aureus adherence to collagen under dynamic conditions. Infect Immun 67:589-594

37. Mårdh PA, Colleen S, Hovelius B (1979) Attachment of bacteria to exfoliated cells from the urogenital tract. Invest Urol 16:322326

38. Carbonero MJ, Pascual A, Martínez-Martínez L et al (1989) Adhesion capacity and surface properties of Staphylococcus epidermidis and Staphylococcus saprophyticus. Enferm Infecc Microbiol Clin 7:466-470

39. Merkel GJ, Scofield BA (2001) Interaction of Staphylococcus epidermidis with endothelial cells in vitro. Med Microbiol Immunol 189:217-223 doi:10.1007/s004300100090

40. Nilsson M, Frykberg L, Flock JI et al (1998) A fibrinogen-binding protein of Staphylococcus epidermidis. Infect Immun 66:26662673

41. National Committee for Clinical Laboratory Standards (NCCLS) (1999) Methods for determining bactericidal activity of antimicrobial agents. Approved guideline M26-A. NCCLS, Wayne, PA 